\title{
A PROFILE
}

\section{Dr med Friedrick-Wilhelm Meinecke, M.D., Hamburg}

\author{
Medallist, I982: The International Medical Society of Paraplegia
}

DR FRED MEINECKE who was born in I920, had a distinguished War Service, in which he was severely wounded. His medical studies took place in the University of Bonn, and after his internship in Medicine and Neurology, he specialised in Orthopaedic Surgery at the famous Bergmannsheil Accident Hospital at Bochum (Ruhr area) under Professor Buerkle de la Camp.

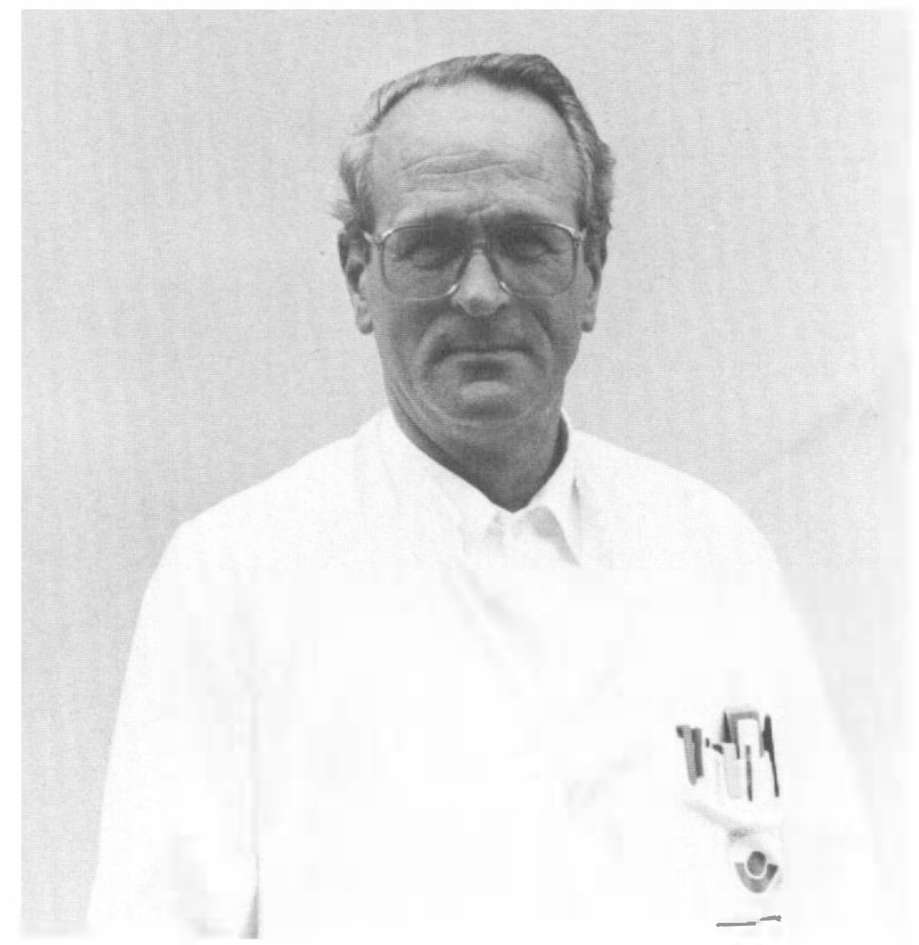

It was there that he subsequently instituted a Spinal Injury Unit; in fact, one of the first to be established in Germany. His Unit soon became a highly regarded institution for paraplegic and tetraplegic patients in Germany.

In the early I950s, he made contact with the late Sir Ludwig Guttmann, and the National Spinal Cord Injury Centre in the Stoke Mandeville Hospital, and became one of the founder Members of the International Medical Society of Paraplegia, and one of the late Sir Ludwig's most successful pupils.

From 1974-79, Dr Meinecke was Director of the Research Institute 
for Traumatology of the Board for Workmen's Compensation at Frankfurt upon Main.

He has published an impressive list of scientific papers, and has at the same time organised a highly effective system for information and cooperation amongst German Spinal Cord Injury Units, including a day and night service. There are regular six monthly meetings for scientific discussion and co-operation, concerning documentation and administration.

In I979, Fred was elected to plan and design the new Spinal Cord Centre in Hamburg, and on its completion was appointed Medical Director of this outstanding Unit.

Our Medallist, is a Regional Editor of our Journal, and is a member of the Executive Committee of the International Stoke Mandeville Games Federation; he is also a Member of the Medical Commission of Rehabilitation International, and is Vice-President of the German Association for Brain Traumatology, and Secretary of the Society for Research of the Spine.

Fred has been well known to many of us for more than 20 years, and always takes an active part in our Scientific Meetings and certainly, is always ready to ask questions and to participate in discussions.

The International Medical Society of Paraplegia decided that it would be most appropriate to award Dr Fred Meinecke the I982 Medal of Honour to this outstanding Member of our Society, who is a pioneer in the field of active medicine as well as in scientific research in spinal cord injury. 